
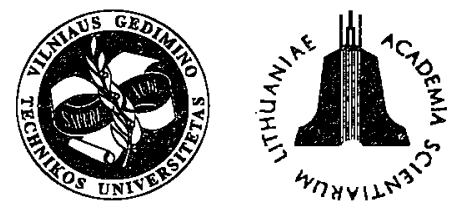

ISSN 1648-4142 TRANSPORT

http:/www.vtu.lt/english/editions

\title{
THE RESEARCH IN TO PASSENGERS' TRANSPORTATION BY LAND TRANSPORT AND THE FORMATION OF FORMALIZED MODELS
}

\author{
Jonas Butkevičius, Algis Žvirblis \\ Dept of Transport Management, Vilnius Gediminas Technical University, \\ Plytines g. 27, LT-2016 Vilnius, Lithuania.E-mail: vladas@ti.vtu.lt
}

Received 200210 29; accepted 20030228

\begin{abstract}
The analysis of the Lithuanian passengers' transportation market has been carried out as well as the analysis of passengers' transportation by land transport, on the basis of which the most important problems causing areas of local, intercity as well as international transportation have been identified.

Systematically evaluating passengers' transportation market on the city's scale as well as the complex character of passengers' transportation by urban public transport, formalized models enabling us to solve the entire complex of tasks related to the problems of passengers' transportation have been worked out. Identifying a necessary summative effect in terms of social and economic factors a model for railway transport market which would correspond to that market specificity has been formed.

These models can be employed to carry out the calculations needed to determine internal and international routes.
\end{abstract}

Keywords: public transport; market analysis; formalised models; systematic analysis; optimisation tasks.

\section{Introduction}

Prospective issues of passengers' transportation should be solved evaluating the importance of the transport sector for the country's economy, its role in determining strategies for the economic growth as well as estimating the significance of the mentioned sector's for the country's population. In spite of the liberalization of many sectors including the transport one, passengers' transportation will still be influenced by the country's policy. It is determined by the necessity to satisfy the country's populations' social needs as well as by its impact on the country's regions further growth. Thus, the problems of passengers' transportation are urgent from theoretical and practical points of view and, hence, are elaborated in many authors' works. Since road and railway transport carries the main amount of passengers, the theoretical basis able to analyse the land transport should be formulated.

The carried out detailed investigations evaluate passengers transportation by road transport means including intersity, local as well as city public (buses and trolleybuses) routes $[1,2]$ have enabled to identify some empirical differences. The modelling of the frequency of journeys [1] has also been conducted. However, a lack of theoretical works can still be noticed which would discuss in detail passengers' transportation.

Tasks of formalization in transport investigated in many works [2-5] do not include the most common cases characterizing passengers' transportation by land transport means. Having discussed the formalized models , the analysis of resources $[6,7]$ showed that the problems of this kind can be solved on the basis of the general optimisation principles and the evaluation of the transport services competitiveness can be accomplished applying the Pontriagin principle [8]. While proceeding with the theoretical investigations, our research paper provides the market volumes defined on the analyses basis, the models of local and intercity passengers' transportation as well as passengers' transportation by city public transport and railway. The paper puts forward some application possibilities.

\section{The Analysis of Passengers' Transportation Mar- ket}

The general market volume of passengers' transportation in the most common case will be equal to:

$$
Q=Q_{K}+Q_{G}+Q_{V}+Q_{O},
$$

where $Q_{K}, Q_{G}, Q_{V}$ ir $Q_{O}$ - are the corresponding market volumes of passengers' transportation by road, rail, internal waterways and air transport means.

It should be noted that the market of passengers' transportation by the internal waterways transport in the forms of the internal transportation is very scarce and is carried out by the main internal waterways route, i.e. the Smiltynes ferry people are ferried annually there, which makes up only $0,37 \%$ of the overall country's passengers' transportation, in other words it is $0,38 \%$ of the overall internal transportation (Fig 1). 

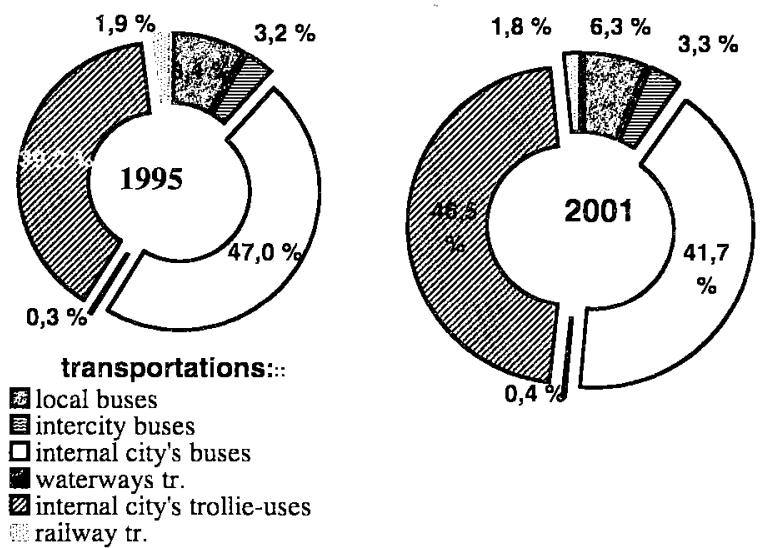

Fig 1. The percentage distribution of the Lithuanian internal passengers' transportation market among various transport kinds in 1995 and 2001
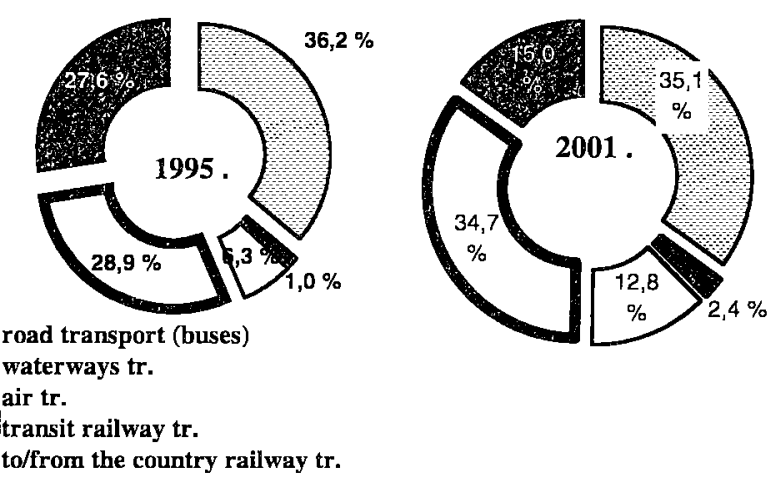

waterways tr.

transit railway tr.

so/from the country railway tr.

Fig 2. The percentage distribution of the international passengers' transportation market among various transport kinds in 1995 and 2001

Air transportation occupies even a smaller share of the internal passengers' transportation market, i.e. out of $355,87 \mathrm{mln}$. passengers' transported in 2001 there were only $0,363 \mathrm{mln}$. passengers carried out by air. This constitutes only $0,1 \%$ of the entire market. Due to the country's small territory and rather high nominal value of the internal transportation by air, this type of transportation in very uneconomical and actually undeveloped in Lithuania. Only 1,4 thousand passengers are annually transported by the sole internal air route Kaunas Klaipeda. That constitutes only $0,0003 \%$ of all internall passengers'.

As far as the market share of the international passengers' transportation by air is concerned, it should be noted that it is growing. In 1995240,3 thousand passengers' used air services, which made up 6,3\% of all international passengers whereas in 2001 the amount of these passengers went up to 362,7 thousand, which amounts to $12,8 \%$ of the overall international market (Fig 2).

Therefore, evaluating the entire market of the country's passengers' transportation, it is evident that the impact of the transportation carried out by the internal waterways on this market is minimal and air transporta- tion does not influence the country's internal market and occupy an insignificant share $-12,8 \%$ of the international market. Having analysed the statistical data, we can state that the principal share of the country's passengers' transportation market is made up by land transport which carries $99,5 \%$ of all the passengers', $99,6 \%$ of the internal passengers' and $84,8 \%$ of the international ones. Hence, it is a matter of utmost importance of this kind of transport.

\section{The Analysis of the Market of Passengers' Trans- portation by Land}

The market volume $Q_{S}$ of passengers' transportation by land is equal to:

$$
Q_{S}=Q_{K}+Q_{G} \text {. }
$$

The market volume of passengers' transportation by road will be equal to:

$$
Q_{K}=\sum_{i} \sum_{k} Q_{i k}+\sum_{j} \sum_{e} Q_{j e}+\sum_{m} Q_{m}+\sum_{p} Q_{p},
$$

where $i$ - is a city's index; $k$-a city's route index $; j-\mathrm{a}$ suburbian index; $e-$ a suburbian route index; $m-$ an intercity route index; $p$ - an international route index.

The analysis of the city's (urban) transport market shows that in 1995 bus transportation in the cities made up $47,0 \%$ of the overall country's internal transportation, trolley-buses constituted $39,2 \%$ of the internal transportation. In 2001 bus and trolley-bus transportation in the cities constituted $51,3 \%$ and $46,5 \%$ of the overall internal transportation correspondingly. In 1995 passengers' transportation in the cities constituted $88,2 \%$ of the overall passengers' transportation by road whereas in 2001 urban public transportation amounted to $90,1 \%$.

In 2001 the intercity passengers' transportation by bus made up 3,1 \% of the overall country's internal transportation and $3,2 \%$ of all the country's internal transportation by road.

The market volume of passengers' transportation by rail will be equal to:

$$
Q_{G}=\sum_{l} Q_{l}+\sum_{t} Q_{t}(l=1,2, \ldots r ; \mathrm{t}=1,2, \ldots \mathrm{z}),
$$

where $l$ and $t$ - are the indices of local and international railway routes correspondingly.

In 1995 and 2001 passengers' transportation by rail amounted only $2,2 \%$ of the overall country's passengers' transportation.

In 1995 local passengers' transportation by rail made up $1,9 \%$ of the all country's internal passengers' transportation whereas in 2001 it was only $1,8 \%$.

In 1995 international passengers' transportation by rail constituted $56,5 \%$ of all the country's international transportation whereas in 2001 its share went down to $49,7 \%$.

It should be emphasized that Lithuania serves as the 
platform through which a transit railway passengers' stream flows from Kaliningrad to Russia. Therefore it is crucial to distinguish passengers' flows to/from the country and transit flows. In $199548,9 \%$ of all the international railway passengers' flows were to/from the country whereas in 2001 their share decreased to $14,4 \%$. As we see transit railway passengers' flows constituted 51,1 $\%$ in 1995 and amounted to $85,6 \%$ in 2001 .

Since 1995 the amount of passengers using the country's railway services and the in railway transport market share is steadily decreasing due to various reasons. As in the whole Europe the Lithuanian people's income is growing, especially of urban residents and there is an increasing number of privately - owned automobiles. In the period of 1990-2001 their amount went up from 128 to 304 for 1000 country's resident, i.e. it increased by 2,4 times. It is feasible that this tendency will remain in the future altogether with the population's growing purchasing power if drastic measures are not taken. The basic reasons for such a decline are associated with the decreasing of railway services (slow speed, old carriages, lack of comfort and privacy).

Moreover, buses and private automobiles are much more convenient not only for the people living in the villages, but also for those living a long way from railway stations (15-20 min or longer) and having to commute to work or school.

In many cases buses and certainly cars ensure greater comfort and shorter time as compared with uncomfortable, old and slow trains which are the result of the insufficient infrastructure. Anyway privately - owned automobiles and public buses in Lithuania, as it is observed everywhere in Europe, will be the main competitors of the railway services. As far as the international interconnection is concerned there will be a constant increase in the competitiveness of the air services.

Market peculiarities of passengers' transportation determined by these investigations revealed necessity to carry out analytic problem analysis. But the analysis should be based on theoretical preconditions.

\section{The Formalized Models for the Market of Passen- gers' Transportation by Land}

For the purpose of our further analysis of the issue the market should be defined in such a way as to be able to evaluate the changes that are determined by the constantly changing needs of the passengers' transportation by road and rail and the interaction between these types of transportation. This is shown in the analysis of correlative connections.

The given research paper [3] presents a formulated model of railway and road transport interaction (the former is aimed at helping to solve the tasks concerning the compatibility of these two types of transport at terminals). The model is based on the condition of maximization of rails application if there is a certain restrictive system. Hoverer, it cannot be applied to passengers' transportation by road or rail.

Applying a systematic approach we have to analyse the country's internal potential market $\mathrm{A}$ of the passengers' transportation as a single solid system with operating market $A^{\prime}$ ' of the intercity passengers' transportation as well as A" of the local passengers' transportation. The quantity of these potential markets can be estimated using certain statistical data. The basic principle established here is as follows: despite of the fact that passengers' transportation are carried out by many various firms (having different statuses), all the transportation have to be conducted on the basis of limited resources and first of all limiting the overall expenditure. This is done in accordance with the state's attitude forwards the country's transport system.

The analysis has shown that the theoretically based solution of the task is the one that includes all three levels, thus, the task can be formulated in accordance with the criterion of the composite expenditure $S$ as follows:

$$
\min _{\mathrm{a} \in\{\mathrm{A}\} \mathrm{an}^{\prime} \in\left\{\mathrm{A}^{\prime}\right\} \mathrm{a}^{\prime \prime} \in\left\{\mathrm{A}^{\prime \prime}\right\}}\left\{\overline{\mathrm{S}}\left(a, a^{\prime}, a^{\prime \prime}\right)\right\},
$$

where $S\left(a, a^{\prime}, a^{\prime \prime}\right)$ - is a vector defining the composite expenditure of the volume of the actual passengers' transportation; $a$ - the volume vector belonging to infinity $\{A\}$ of passengers' transportation on the country's; $a^{\prime}-$ the volume vector belonging to infinity $\left\{A^{\prime}\right\}$ of the intercity passengers' transportation; $a$ " - the volume sector belonging to infinity $\left\{A^{\prime \prime}\right\}$ of the local passengers' transportation.

To solve this task a system of restrictions should be formulated which can be analysed only having given a concrete expression of the task being solved and having narrowed it. Anyway it will be the task of big dimension programming.

Studying passengers' transportation by urban transport means, the case, i.e. how bus and trolley-bus routes operate should be examined. Therefore in accordance with $S_{m}$ criterion we will have the following task expression:

$$
\min _{\mathrm{k}_{1} \in\left\{K_{1}\right\} \mathrm{min}_{2} \in\left\{K_{2}\right\}}\left\{\mathrm{S}_{m}\left(k_{1}, k_{2}\right)\right\},
$$

where $S_{m}\left(k_{1}, k_{2}\right)$ - a vector defining the overall expenditure of the actual passengers' transportation volume by city public transport; $k_{1}$ - the volume vector belonging to infinity $\left\{K_{1}\right\}$ of passengers' transportation by bus, $k_{2}-$ the volume vector belonging to infinity $\left\{K_{2}\right\}_{\text {of }}$ passengers' transportation by trolley-bus.

It should be stressed that in this case it is necessary to estimate the dynamic changes which are caused by the needs of the transportation of the above-mentioned kinds of transport as well as their interaction.

Analysing passengers' transportation by rail and distinguishing this kind of transport as an independent one as well as evaluating its specificity (infrastructure, trans- 
port means, routes formations) we should encompass the minimization of the expenditure concerning both individual routes and local routes. Thus, according to $S_{G}$ criterion we would come up to the following expression:

$$
\min _{t_{1} \in\left\{T_{1}\right\} \min _{2 l} \in\left\{T_{2 l}\right\}}\left\{S_{G}\left(t_{1}, t_{2}\right)\right\}, l=1,2, \ldots, r
$$

where $S_{G}\left(t_{1}, t_{2}\right)$ - a vector defining the overall expenditure of the actual passengers' transportation volume by rail; $t_{1}$ - the volume vector belonging to infinity $\left\{T_{1}\right\}$ of passengers' transportation by rail along all the routes; $t_{21}$ - the volume vector belonging to infinity $\left\{T_{2 l}\right\}$ of passengers' transportation in each from 1 local routes.

The corresponding restrictive systems for models (6) and (7) should be formulated. Moreover, it is essential to give a concrete expression of the expenditure vector.

A formalized model corresponding to a single separate route and being as the foundation for the analysis and substation of this route will be grounded and verified if a complex of the factors determining its efficiency will produce a necessary and sufficient summative effect $E$ in terms of a social and economic development.

The carried out analysis has enabled us to distinguish these principal factors making up the identified complex: tariff $T$, passenger index $K$, social factor $S$, infrastructure state $P$. They are of utmost importance determining complex criteria - effect $E$.

The model expresses the dependence of vector $E$ on each of the main local effect vectors $E_{T}, E_{K}, E_{S}$ and wholeness $E_{P}$ though the scalar form of they influence on vector $E$ thus correspondingly we have $P_{T} P_{K^{\prime}} P_{S} P_{P}$ :

$$
E(T, K, S, P) \rightarrow \begin{gathered}
P_{T} \\
P_{K} \\
P_{S} \\
P_{P}
\end{gathered},\left[\begin{array}{c}
E_{T} \\
E_{K} \\
E_{S} \\
E_{P}
\end{array}\right]
$$

The influence scalar matrix corresponding the given task:

$$
\begin{array}{llll}
P_{T T} & P_{T K} & P_{T S} & P_{T P} \\
P_{K T} & P_{K K} & P_{K S} & P_{K P} \\
P_{S T} & P_{S K} & P_{S S} & P_{S P} \\
P_{P T} & P_{P K} & P_{P S} & P_{P P}
\end{array}
$$

Analysing the system of two principal factors: tariff $T$ and passengers' indicator $K$, we will have the following expression of this model which can be applied to the task:

$$
\bar{E}\left(T, K^{r}\right)=P_{T T} \bar{E}_{T}+P_{T K} \bar{E}_{T}+P_{K T} \bar{E}_{K}+P_{K K} \bar{E}_{K} .
$$

The impact of the interaction of these two factors is here estimated by means of quantities $P_{T K}$ and $P_{K T}$.

This can function as the basis for solving the task of maximizing effect $\vec{E}(T, K)$ which can be formulated (by extending the classical solution algorithm of the analogical task) as search for the maximization of functional $J$ :

$$
\max J=\int_{t} F(E, \dot{E}, t) d t
$$

where $F(E, \dot{E}, t)$ - is a function the extent of effect $E$ and its changes in time (quantity $\dot{E}$ ).

The Euler's principle used to solve this problem defines the range of solutions as a certain isoperimetric figure.

Using these models further passengers transportation experimental investigations are made.

\section{The Research into the Optimal Route}

It is expedient to apply formalized models analysing all bus and trolley-bus routes in various directions especially where these routes duplicate and on the basis of the carried out investigations the most optimal kind of transport should be chosen on the country's scale.

The preliminary estimations conducted in accordance with these models have shown that the main passengers' flows on such routes as Vilnius - Kaunas, Kaunas Klaipeda, Vilnius - Turmantas and Vilnius-Varèna should be carried by fast trains whereas the local bus traffic should be coordinated with the train traffic so that it could transport the passengers across the region. In such a way a new transportation technology is being developed - fast local connections. On the above mentioned route a logical travelling chain should be elaborated for the passengers, i.e. travelling - transferring, which would comprise city transfers as well as suburban transfers from the local bus transport means to trains and vice versa.

The research has proved that it is advisable to introduce new transportation technology in the country - combined passengers' transportation, i. e. "railway - bus" routes: Vilnius-Kretinga-(Palanga)-Klaipeda; VilniusMarcinkonys-(Druskininkai); Vilnius--Švenčionèliai(Utena); Kaunas - Marijampolè - Šeštokai - (Alytus).

It is advantageous to organize passengers' transportation by bus from Kaunas to Jonava near „Baltija“ and "Pajūris" trains and carry them back to Kaunas as soon as they get off the trains. Besides, it is advisable to transport the passengers who travel by „Baltic“ and ,Seaside " trains from Kretinga to Palanga and back using the transport services. That enables us to deliver the passengers to Palanga main holiday homes.

The preliminary calculations have demonstrated, that having laid superfast railway routes Berlin-WarsawŠeštokai-Kaunas (or Vilnius)-Šiauliai-Ryga-Tallinn (with its branch to Saint Petersburg), the super-fast railways would take over:

- $\quad$ some share road transport - 40-50\% of the market concerning the routes extending up to $300 \mathrm{~km}$ (the routes to Warsaw, Ryga) and 60-90\% of the market concerning the routes extending over $300 \mathrm{~km}$ (routes 
to Tallinn, Berlin, Hamburg, Amsterdam, Paris and etc);

- $\quad$ some share of air transport - more than $80 \%$ of the market retaking to the routes, travelling by which would take about two hours using the super-fast transport (the routes to Warsaw, Ryga), more than $50 \%$ of the market of the routes taking up to four hours and $20-30 \%$ of the market of the routes taking four on six hours (the routes to Berlin, Amsterdam and etc).

\section{Conclusions}

1. The necessity to satisfy the population's social needs, to influence the further development of the country's regions determines the fact that passengers' transportation in Lithuania and first of all by railway will remain under the influence of country's policy.

2 . The principal share of the passengers' transportation market is comprised by land transport. Since 1993 the number of passengers using railway services as well as their market share has been diminishing, and the main share of the country's internal transportation is made by bus and trolley-bus transportation in the cities $(41,7 \%$ and $46,5 \%$ correspondingly 2001 ). The principal share of the international passengers' transportation is carried out by rail $-49,7 \%$ (where transit transportation constitute $34,7 \%$ and to from the country $-15,0 \%$ (2001).

3 . Systematically evaluating passengers' transportation market as a solid single in accordance with the principle that transportation should be carried out on the basis of restricted (limited) resources and first of all limiting overall expenditure, the models have been formalized concerning passengers' transportation on the country's scale and in the cities. These models can serve as a scientific background solving the task of composite formation of the country's transport system.

4. Evaluating the railway transport specificity in accordance with the criterion of the minimization of the overall expenditures concerning a single route as well as all local ones the models have been made that enable us to find a necessary and sufficient social - economic summative effect.

5. Concluding we can state that the formulated principles as well as the models crucial for solving of the main issues enable us to deal with the whole complex of tasks associated with the passengers' transportation and also scientifically substantiate the made decisions. This is illustrated in the research into individual routes.

\section{References}

1. Butkevičius, J. Modelling of the Dependence of Travel Frequency on the Length and Duration of a Journey, Improvement of City Passenger Transport Systems. Transport, 2002, Vol XVII, No 6, p. 223-225.

2. Livshitz, V. N. Systemic analysis of economic processes in transport. Moscow: Transport, 1986, 240 p. (in Russian).

3. Baublys, A.; Petrauskas, B. Transport terminals. Monograph. (Transporto terminalai). Vilnius: Technika, 2002. 286 p. (in Lithuanian).

4. Friesz, T.; Bernstein, D.; Stough, R. Dynamic Systems, Variational Inequalities and Control Theoretic Models for Proedicting Time-varuing Urban Network Flows. Transportation Science, 1996, Vol 30, p. 14-31.

5. Blank, R. M. When Can Public Policy Makers Rely on Private Markets? The Effective Provision of Social Services. The Economic Journal, 2000, Vol 110, No 462, Blackwell Publichers Ltd Oxford, UK and Boston, USA, p. 34-49.

6. Ciancimino, A.; Inzerillo, G.; Palagi, L. A Mathematical Programming Approach for the Solution of the Railway Yield Management Problem. Transportation Science, 1999, Vol 33, p. 168-181.

7. Yang, H.; Wong, S. C. A Continuous Equilibrium Model for Estaming Market Areas of Competetive Facilities with Elastic Demand and Market Externality. Transportation Science, 2000, Vol 34, p. 216-227.

8. Žvirblis A. The Principles of Analysis Competitiveness and Control Scemes in Transport Services. Transport, 2003, Vol XVIII, No 2, p. 57-60. 